\title{
FLOOD ADAPTATION BY INFORMAL SETTLERS IN KATHMANDU AND THEIR FEAR OF EVICTION
}

\author{
NEERAJ DANGOL \& JENNIFER DAY \\ Faculty of Architecture, Building and Planning, The University of Melbourne, Australia.
}

\begin{abstract}
Informal settlements in Kathmandu are increasing in size and number. The housing demand in the city is rising due to the population growth and rural-urban migration, resulting in rising housing price. The high cost of housing means it is difficult for the low-income group to afford necessary housing. The government has not addressed the necessity of affordable housing for the low-income group. In this situation, some people of low-income build their dwellings on public land without legal title. This phenomenon has added to the number of informal settlers in the city. Most of the informal settlements in Kathmandu are located in the floodplains of rivers, putting them at flood risk. Annual monsoon season flood incidents in recent years demonstrate how these riverbank informal settlements are at risk. Informal settlers need to take initiatives themselves to reduce their flood risk as the government assistance is absent. Moreover, the government considers the informal settlements unlawful as they are built on public land without any authority. Therefore, there is always the possibility of their eviction by the government. The study investigates how informal settlers perceive their fear of eviction and how the fear influences their flood adaptation. The study pursues the qualitative approach to understand and analyse the informal settlers' fear of eviction and their flood adaptation. Semi-structured interviews were conducted in 41 houses from three informal settlements situated along the largest river of Kathmandu called the Bagmati River. The flood adaptive measures implemented in these houses were also identified. The study finds that the informal settlers can be encouraged for the flood adaptation by reducing their fear of eviction.
\end{abstract}

Keywords: fear of eviction, flood adaptation, informal settlement, Kathmandu.

\section{INFORMAL SETTLEMENT}

Defining informal settlements is complex in a universally accepted manner [1]. However, UN-Habitat has proposed the operational definition of a slum [2]. According the definition, a slum household is defined as a household lacking one or more of the following: improved water; improved sanitation; sufficient living area; durable housing (location and permanency of structure); and secure tenure. Among these indicators, some are more distinctly applicable than others to characterise the informal settlements in Kathmandu. For example, considering permanency of house, many houses in informal settlements can be considered not permanent because they are constructed using sacks, bamboo, plastic sheet, wood, metal sheet, mud and other temporary and semi-permanent materials (Lumanti, 2008). Some houses combine temporary and permanent material constructed with low-quality workmanship. Location wise, most of informal settlements in Kathmandu are situated at hazardous sites such as flood prone riverbanks and landslide prone steep slopes. Therefore, hazardous location and lack of permanency of houses are visible characteristics of informal settlements in Kathmandu.

Another indicator which is clearly applicable to characterise the informal settlements in Kathmandu is tenure security. All the informal settlements in Kathmandu are situated in public lands without legal title [3]. The informal settlements the study is investigating are situated at the riverbanks, which are the public lands. Informal settlers in Kathmandu are called 'Sukumbasi', which literally means 'landless people' in Nepali. Therefore, informal 
settlements or Sukumbasi settlements in Kathmandu are distinguishable based on the lack of legal tenure. Because of the lack of legality, these settlements are not recognised by the administration and they do not have the formal address.

Informal settlements are increasing in size and number in Kathmandu. The survey conducted in 2008 by Lumanti, a non-governmental organisation working with the informal settlements, shows that the informal settlements in Kathmandu expanded from 17 smaller to 40 larger settlements from 1985 to 2008 [3]. In 2008, the population of informal settlers was 12,726 as per the survey. In 2013, two informal settlers' organisations conducted another survey of informal settlements in Kathmandu. Their survey shows 24,021 settlers were living in 46 informal settlements in Kathmandu in 2013. This means the population grew almost double in 5 years period.

\section{STUDY AREA AND METHOD}

Among the riverbank informal settlements in Kathmandu, the study selects settlements indicated by red dots in the following Figure 1 as its study area. The red oval groups seven settlements, which are located close to each other. These seven settlements are considered in a cluster, which is named as Shantinagar taken from the name of the area. Other two settlements are Bansighat and Shankhamul. These settlements are selected as the study area because they are situated along the largest river of the city, the Bagmati River, which has the larger population of informal settlers than other rivers; and these settlements are within the boundary of Kathmandu Metropolitan City (KMC).

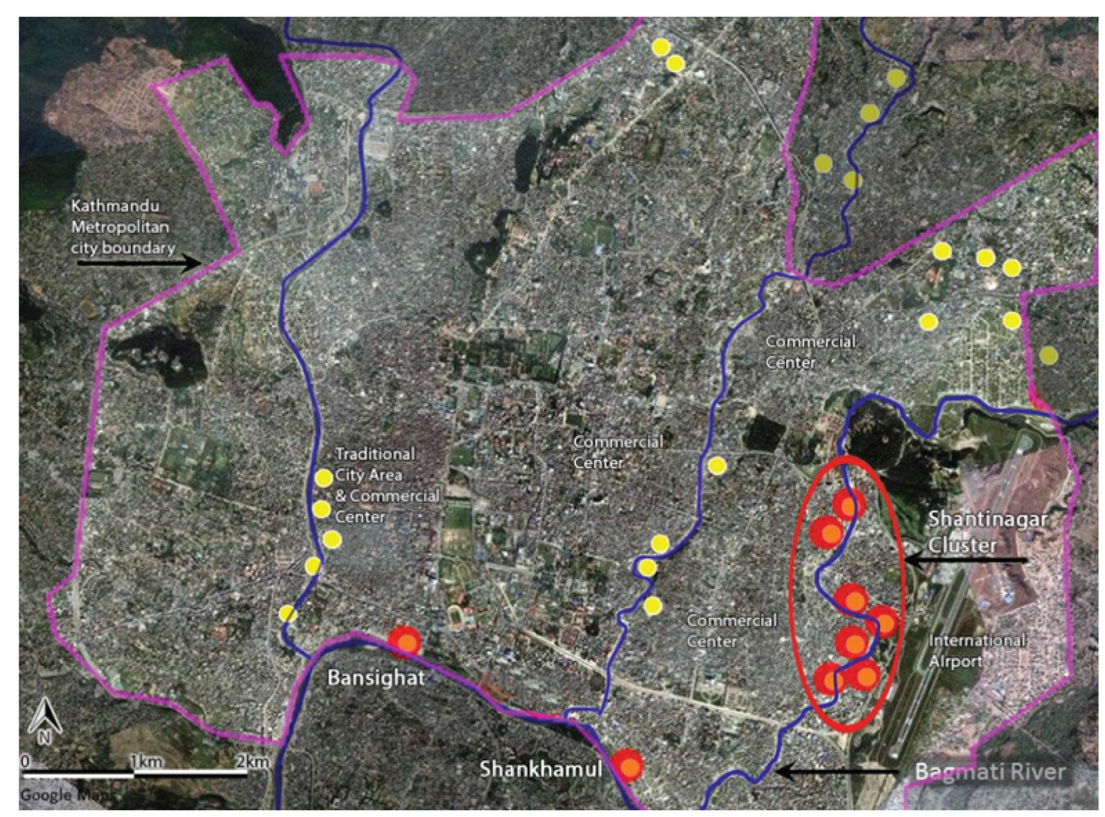

Figure 1: Location of informal settlements in Kathmandu where red area represents selected study area, and yellow dots represent other informal settlements. Blue lines are rivers and the purple line shows the boundary of Kathmandu Metropolitan City (Source: Satellite image from Google Map). 
Table 1: Total number of houses in the settlements of study area and sample size for semistructured interviews.

\begin{tabular}{lll}
\hline Informal Settlements & No. of houses in settlements & No. of sample houses \\
\hline Shanti Nagar Cluster & 693 & 27 \\
Bansighat & 180 & 7 \\
Sankhamul & 105 & 7 \\
Total & 837 & 41 \\
\hline
\end{tabular}

(Source: Nepal Basti Basobas Samrachhyan Samaj and Nepal Mahila Ekta Samaj, 2013.

They are informal settlers' organisations)

The study pursues qualitative approach to understand informal settlers' fear of eviction and to identify their flood adaptive measures. The qualitative data are collected through semi-structured interviews and observations and analysed through thematic analysis. Purposive sampling is applied for to decide the sample houses for interviewing. The location and the physical features of houses were considered for the sampling purpose to obtain variety in the resulting sample for interviews. The gender balance of interviewees was maintained as far as possible. The unit of analysis is the housing unit, which is appropriate because the paper investigates the physical flood adaptation in informal settlers' houses. The households living in the housing units were approached for the data collection.

Regarding the sample size, the study intended to continue interviewing until theoretical saturation was achieved. Forty-one semi-structured interviews were conducted to achieve the theoretical saturation in all three settlements. The numbers of sample houses from each settlement for the interview are shown in the Table 1 below.

\section{FLOOD IMPACTS}

Findings from interviews and observations show many of informal settlers in the study area are affected by flood incidents. Most of flood incidents occurred during monsoon season from June to September. During this season Kathmandu receives major portion of its annual rainfall causing increase in water level in the rivers (Figs 2 and 3). The rivers also collect storm water from the city through drains contributing in river level rise.

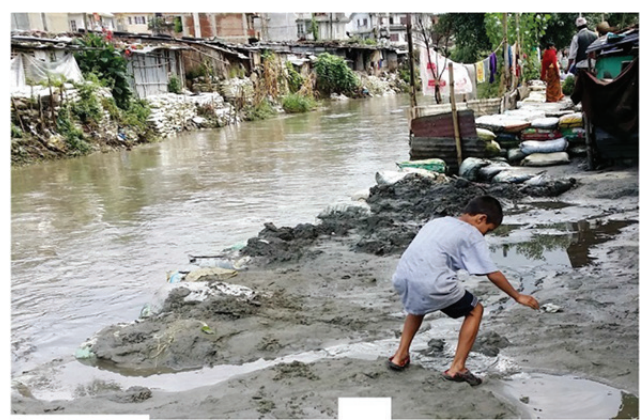

Figure 2: The increased river level after a rainfall in Shantinagar (Source: Author).

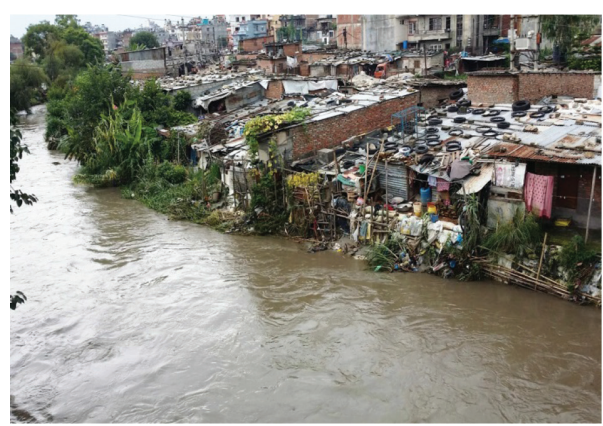

Figure 3: Houses adjacent to the raised water level in Shantinagar (Source: Author). 
Following flood impacts are observed in the study area and learned from respondents.

- The housing structures get damaged or affected by the flood. For examples, walls made up of wooden plank, corrugated metal sheet or other lightweight materials get washed away or damaged by floor water. The wall facing to the river gets more damages. In some cases, flood also damages walls made up of robust materials such as brick or cement block. In these cases, flood water washes away soil underneath of the house weakening the foundation or support below walls.

- Several respondents shared how the flood damages their belongings every year or more than once in a year. Damages are more when the flood occurs unexpectedly because they do not get time to move their stuff in safer locations. Many of them lost their furniture, bed, mattress, clothes, utensils, groceries and textbooks. Even if they manage to prevent of washing away of their stuff by closing the doors and windows, they all get wet and damaged. Some of them even shared how they could not save their food and stayed hungry in following days.

- Many of residents, whose house got flooded, had to spend nights outside for a few days. They manage to drain out flood water in a few hours by digging waterway (channel) and bucketing up; however, it takes a few days to clean the mess caused by the flood. They need to dry the stuff which are reusable and throw other damaged ones. Additionally they also have to guard their belongings which they put outside before they get caught by the flood. Some of them also shared they lost their belongings when they put outside.

- It takes time for residents to come back to their normal life after flood incidents as they need to rearrange and manage everything affected by the flood, as explained in the previous point. During this period, they miss their working days for around a week and kids miss their school.

- Some respondents shared their experience of about to get drowned in the flood. For example, a lady in Shantinagar settlement got stuck in her house in a flood in the night in 2015 when the water level reached up to her neck. She managed to get out from the house but she hurt her leg stepping on something sharp and had to have treatment for a month. Similarly, a fourteen year old girl was trapped in the flooded house (Fig. 4) in Bansighat settlement in 2016. It also occurred in the night time when all other family member except her managed to escape from the house. Later, the police came and helped her to get out using rope. She was sick for several days because of cold and fear. An elderly man in Shantinagar shared how he ran through the roof carrying a kid as it was hard to escape from the door. These are some of examples of how residents' lives are at flood risk.

- Many residents mostly kids get cold, fever, itching skin, diarrhoea after flood incidents. The river itself is polluted because city sewerage gets mixed into the river without any treatment. Moreover, the sewerage running through the settlement also overflows because of river flood (Fig. 5). Contact with the polluted water causes waterborne and skin diseases. Similarly, getting wet in the flood causes cold and fever. Additionally, sleepless nights outside the house and anxieties make flood affected residents health more vulnerable.

- When the flood water enters into the sewer pipes in the settlements, the sewer water springs up blowing the manhole lids (Fig. 5). This worsens the flood in the settlement by adding sewer water. When flood water enters into the sewer pipes, it also causes a backflow of sewer water through toilets in the houses. 


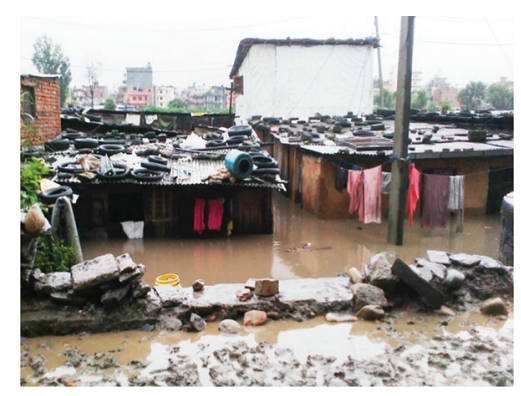

Figure 4. Houses get flooded in Bansighat (Source: an interviewee).

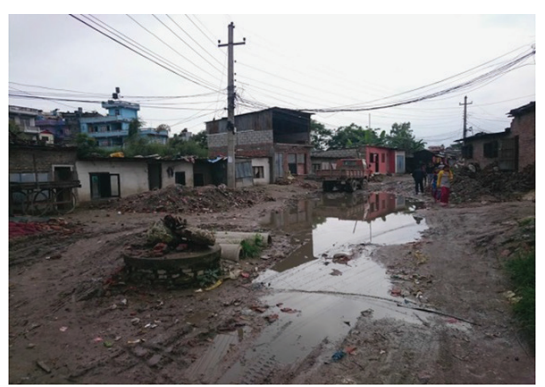

Figure 5. Flooded road in Shantinagar and stones are put on the manhole cover to prevent overflow (Source: Author).

\section{FLOOD ADAPTATION}

In defining adaptation, the literature focuses on a system's ability to cope. For example, Brooks [4], defines adaptation as 'adjustments in a system's behaviour and characteristics that enhance its ability to cope with external stresses.' Similarly, Pelling [5] defines adaptation as 'the process through which an actor is able to reflect upon and exact changes in those practices and underlying institutions that generate root and proximate causes of risks, frame capacity to cope and further rounds of adaptation of climate change.' Both definitions present system's or actor's ability to cope with external stresses or risks as an important aspect of adaptation. It is important to have adaptive capacity to implement the adaptive measures; however there is also the possibility that people may not implement the adaptive measures even they are able to do. The study identified the measures of flood adaptation implemented by informal settlers in their houses from observations and interviews. Following are the identified adaptive measures:

- Raising the ground floor (plinth) level by filling with soil, sand, stone and bricks. The ground floor level is raised depending on the past experience of the flood. Four feet to ten feet rise in the floor level was observed. When the floor level is raised, nine inch thick brick wall is constructed as the foundation or support to hold filled materials and superstructure.

- In the case of houses adjacent to the river, sandbags are piled up to protect the foundational brick wall below ground level. Piles of sandbags are supported by the bamboo and reed sticks (Fig. 6).

- Soling the floor with brick and finish the floor with cement plaster so that flooded water in the house can be drained out quickly. It also reduces seepage or dampness from the floor.

- Adding an upper floor (first floor) to protect to be safe from flood and to protect belongings.

- Raising riverside walkways by filling soil, sand and stones and supported by bamboo poles (Fig. 7).

- Changing the outer wall of the house from comparatively temporary materials to rubust ones. For example, residents who had wooden plank or bamboo wall change it to tin (CGI) wall to reduce flood water intrusion. Similarly, who had tin wall convert it into brick or cement block wall to reduce flood impacts. Changing the mud mortar brick wall of a house to cement mortar wall is also a way of changing construction material responding flood impacts. 


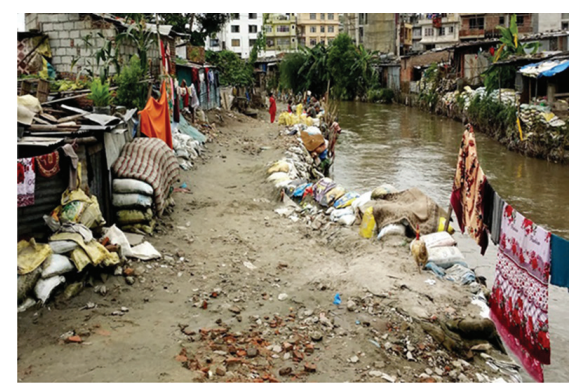

Figure 6: walkway or land next to the river raised by pilling sandbags and filling sand and soil (Source: Author).

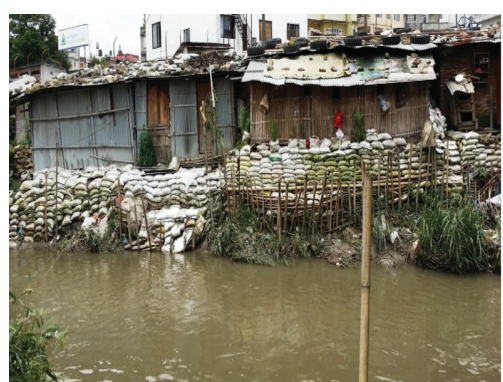

Figure 7: Houses made up by temporary materials raised and supported using piles of sandbags (Source: Author).

- Additional to the ground level rise, residents also raise the threshold of door or platform outside the house to prevent intrusion of flood water.

- Raising the toilet level or moving the toilet to upper floor to prevent backflow from the toilet.

- Plastering the lower level of outer wall to prevent seepage.

- Building boundary walls, if space is available to prevent from flood water.

- Raising furniture height by using bricks and stones.

- Changing CGI sheet at roof and using putting to stop leakage from the roof or use plastic sheet over the roof.

- Providing pipes to drain out flood water from or around the house.

\section{FEAR OF EVICTION}

Informal settlements in the study area are built on public land without any authority which is considered unlawful by the government of Nepal. The Public Crime and Punishment Act - 2027 (1970) [6] prohibits 'to trespass on any governmental or non-governmental office or anyone's building or land by committing riot; or to stay or remain there without any authority.' It clearly implies that occupying the public land is against the law and that the government has legal rights to take action against it. Consequently, the government evicted Thapathali settlement forcefully by bulldozing dwellings in May 2012 leaving 251 families nowhere to go and without any alternatives [7]. Similarly, the government has attempted several times to evict Shankhamul settlement [8] and imprisoned some of the settlers for weeks [9]. When a successful or attempted eviction occurs, it not only affects the settlement where the action occurs but also influences other informal settlers by raising their fear of eviction [10].

All respondents who participated in the interview accepted that they are living on public land and agreed that there is possibility of their eviction by the government any time. However, the study observed that they have different levels of fear of eviction even all of them have no legal title. Based on the analysis of interviews and observations, the study identified factors which affect the level of fear of eviction. These factors are community, recognition of the local administration, informal ownership and experiences of discrimination, humiliation and criminalisation. 
The study found that the sense of being in the community affects the level of fear of eviction in an individual informal settler. More than two-third among 41 respondents mentioned that they have a large community with them and indicated that their belief on the solidarity of the community helps to console them when they feel the fear of eviction. For example, the researcher asked about fear of eviction, a widow living with her daughter in law and grandson said 'I always have fear of getting evicted, but I am not alone in this settlement.' She indicated that she is with community by saying she is not alone in the settlement and it is considerable that she mentioned being in community immediately to compensate her fear of eviction. Similarly, an elderly tailor who actively participates in protests against government actions towards informal settlers, emphasised on the strength of their community. He said 'We are not a few in number we have a large community and we won't keep quiet if the government uses the force to evict us without proper alternative. We are ready to face the bullet but won't leave the place.' This strong statement shows their confidence on the solidarity of the community, which supports them to minimise their fear of eviction.

More than half of respondents mentioned that recognition by the ward office (local administration) affect their fear of eviction. The administrative area of Kathmandu Metropolitan City is divided into 35 wards which are the lowest level of administrative units. Each ward has a ward office. The study observed less fear of eviction in informal settlers when the ward office recognises them. The recognition by the ward office is important for informal settlers because it gives them assurance that their residency in the ward is acknowledged. The ward office is the first place of governmental administration where residents can report their concerns. The ward office is responsible in identifying the residents in the ward and providing them a recommendation letter so that they can apply for citizenship card, for electricity connection, for water supply connection and for other various purposes. Informal settlers who received their citizenship card being local residents of Kathmandu with the help of the recommendation letter obtained from the ward office feel more secure about their residency in the settlement. For example, a respondent who got citizenship card proudly says 'I even got the citizenship card from here (referring the address of the informal settlement). I am now a resident of Kathmandu.' This indicates that they perceive having citizenship referring the address of informal settlement means they are accepted by the government as local residents of the place. This perception provides them confidence to claim that they belong to that place, which consequently diminishes their fear of eviction. In the same way, obtaining a migration certificate from the ward office also contributes in reduction of fear of eviction. Migration certificate shows the person is migrated to the place where they are living from their place of origin and it also proves that they do not own any property at the place of their origin.

The study identified that having sense of informal ownership of the house make informal settlers feel more secure. Informal settlers who have an identity card expressed higher level of sense of informal ownership. The identity card was prepared and distributed to informal settlers in 2004-2005 by Lumanti (NGO working on informal settlements) in coordination with Kathmandu Metropolitan City Office (KMC). Informal settlers living in the study area prior that time received the identity card. The purpose of the identity card was to keep record of informal settlers as mentioned by Lumanti. The informal settlers who have the identity card perceive it as an important document because it supports their recognition as genuine informal settlers who have been living there for more than ten years. A middle aged man, who is a construction worker, proudly shared that 'We have our identity card distributed 10 years ago. It has our pictures with this house in the background. We can use it to show that we are informal settlers living here in this house for many years.' He takes the identity card as an 
evidence to show that he owns the house and that he is living there for a long time. Similarly, the retired army said regarding owning the identity card, 'When Keshav Sthapit was Mayor; we got the identity card which shows we are living here. At that time, our lands were also demarcated and based on that the identity card includes the information....there was a program organized at nearby open area to distribute identity cards to us by then Mayor. It is actually temporary permission for us provided by KMC to live here.' He takes the identity card as an official document containing information about his family, land and house and acknowledge by then Mayor of the city. This makes him believe the document as the temporary permission of them to live in the settlement. These responses clearly show that they have sense of ownership of their land and house because they own the identity card. Therefore, owning the identity card encourage them to be less fearful to eviction.

Discriminative and humiliating behaviours by the government, society and neighbours, who have legal tenure, are identified as a contributing factor in increasing fear of eviction in informal settlers. Most of respondents share their experience of being discriminated in various forms which enhanced their fear of getting evicted. An example of discrimination by government was when the road passing between the informal settlement and the formal neighbourhood was expanded. The government took land only from the area of informal settlements. A lady who lost half of her land and a wall of her house during road expansion expresses her fear saying 'if the road gets expansion further we may lose our house because last time when the road was expanded they (the government) did not touch the formal land at the other side of road but took our land and a wall of our house. We are pushed closer to the river because of the road expansion.' This indicates how informal settlers view discriminative actions by the government on them because when a road is expanded elsewhere, generally lands from both sides are taken. Such experience makes them feel the government does not consider them as residents of the city which increases their fear of eviction.

The study found that informal settlers are criminalised by the government and formal residents for being informal settlers. Experiences of being criminalised make them guilty of being informal settlers. A middle aged lady who had such experience shared, 'When we were adding a floor in our house, people from nearby area (residents with legal title from adjacent neighbourhood) came to tell us now to do. They told us that we do not have legal title and permission to build, so we should stop it. When we did not stop, they brought police and took my husband to the police station. We already added floor at that time, so what to do? The police warned him not to do so anymore and let him go.' She also added to justify the addition of floor, 'Because of the river, we always have fear to get flooded or washed away. We cannot sleep in peace at night. So, adding a floor is necessary to protect ourselves and stuff.' Her expression shows she has fear to get punished for improving house and she is also afraid of formal residents who can complain against her. Likewise, a construction worker lady expressed her fear, 'If we try to improve our house, police van arrives. How we can feel this is ours and how can I can say I have right to live here?' In this way, experiences of being criminalised increase their fear to be punished which does not allow them to feel secure in their settlement. Informal settlers not only have fear from the state but also from formal residents living nearby neighbourhoods because they know formal residents do not like them and can complain against them to the police. Informal settlers feel that formal residents consider them as eyesore.

\section{FEAR OF EVICTION AND FLOOD ADAPTATION}

The study analysed and found that informal settlers who have higher level of fear of eviction do not invest for flood adaptation as much as they could do. They worried if they may lose 
everything if they are evicted next day. For example, a respondent said, 'We don't have money; we have to take loan to improve our house to make it safe from the flood. But if next day, we get evicted or we have to leave place, we will lose everything..... I have that fear..... government is not trustworthy, it can come any day and tell us to leave because this is not our land, this is public land. Then we will have to leave.' Therefore, they decide for adaptation carefully and do not invest at once. They prefer to invest gradually. For example, if they have to change the material of wall from tin to brick, they do one wall at a time. They may take one to two years to change all the walls.

They tend to choose a temporary adaptive measure although they need to repair or replace that measure time to time. For example, they raised the ground level at river edge by filling with sand and soil and support the filled level using piles of sandbags. These sandbags get damaged by the river and washed away and they have to be repaired or replaced time to time. They do not use stone wall to support the filled level because they hesitate to spend for long term by spending more. The reason is they are uncertain when they may get evicted by the government forcefully.

Around half of respondents indicated that the government need not to help them to protect them from the flood. They can protect themselves if the government assures them that they will not be evicted forcefully. A respondent representing this view said, 'If government allows us to live here and provide certain kind of tenure security, the government does not need to do anything for our safety from the flood. We can improve our houses by ourselves. We are ready to avoid our meal for six months and take loans to strengthen our house.'

\section{CONCLUSION}

The riverbank informal settlers take initiatives for the flood adaptation in absence of assistance from the government. However, they are afraid to invest for the adaptation because they have fear of getting evicted anytime. If the government can reduce this fear, informal settlers could enhance their flood adaptive measures. The fear of eviction can be reduced, if the government could assure informal settlers that they will not be displaced without any alternative provision. Such assurance can be provided by communicating with informal settlers, by issuing notice and by introducing and modifying the policies relevant to informal settlers.

\section{ACKNOWLEDGEMENTS}

Australian Government Research Training Program Scholarship, Riady Scholarship, The University of Melbourne, Anna Hurlimann and Richard Tomlinson.

\section{REFERENCES}

[1] Nuissl, H. \& Heinrichs, D., Slums: perspectives on the definition, the appraisal and the management of an urban phenomenon. DIE ERDE-Journal of the Geographical Society of Berlin, 144(2), pp. 105-116, 2013.

[2] Chapter 1: Development Context and the Millennium Agenda, The Challenge of Slums: Global Report on Human Settlements 2003 (Revised Chapter 1). Available at: http:// unhabitat.org/wpcontent/uploads/2003/07/GRHS_2003_Chapter_01_Revised_2010. pdf (accessed 8 October 2016).

[3] Lumanti. Status of squatter communities along the Bagmati River and its tributaries in the Kathmandu Valley. Kathmandu: Lumanti Support Group for Shelter, 2008.

[4] Brooks, N., Vulnerability, risk and adaptation: A conceptual framework. Tyndall Centre for Climate Change Research Working Paper, 38, pp. 1-16, 2003. 
[5] Pelling, M., Adaptation to climate change: from resilience to transformation, Routledge, London, 2010.

[6] Public Crime and Punishment Act - 2027 (1970), (1970).

[7] Ghimire, B., Government evicts Thapathali squatters. The Kathmandu Post, 9 May 2012.

[8] Anjaria, J.S. \& McFarlane, C., Urban navigations: politics, space and the city in South Asia, Routledge, 2011.

[9] Kathmandu Post. UN Park stalled due to squatters. Kathmandu Post, 17 November 2003.

[10] Paul, B.K., Fear of eviction: The case of slum and squatter dwellers in Dhaka, Bangladesh. Urban Geography, 27(6), pp. 567-574, 2006.

https://doi.org/10.2747/0272-3638.27.6.567 